\title{
Chemical Properties of Element 105 in Aqueous Solution: Extractions into Diisobutylcarbinol
}

\author{
By M. K. Gober, J. V. Kratz, H. P. Zimmermann \\ Institut für Kernchemie, Universität Mainz, D-6500 Mainz, Federal Republic of Germany
}

M. Schädel, W. Brüchle, E. Schimpf

Gesellschaft für Schwerionenforschung mbH, D-6100 Darmstadt, Federal Republic of Germany

K. E. Gregorich, A. Türler, N. J. Hannink, K. R. Czerwinski, B. Kadkhodayan, D. M. Lee, M. J. Nurmia, D. C. Hoffman

Lawrence Berkeley Laboratory, University of California, Berkeley, CA 94720, USA

\author{
H. Gäggeler, D. Jost, J. Kovacs, U. W. Scherer and A. Weber \\ Paul Scherrer Institut, CH-5232 Villigen, Switzerland
}

(Received October 28, 1991)

Element 105 / Chemical properties / Halide complex formation / Extraction into a secondary alcohol

\begin{abstract}
Summary
Studies of the extraction of element 105 into diisobutylcarbinol (DIBC) from aqueous $\mathrm{HBr}$ and $\mathrm{HCl}$ solutions were performed on ${ }^{262} \mathrm{Ha}$ and ${ }^{263} \mathrm{Ha}$ produced in the ${ }^{249} \mathrm{Bk}\left({ }^{18} \mathrm{O}, 5 \mathrm{n}\right)$ and ${ }^{249} \mathrm{Bk}\left({ }^{18} \mathrm{O}, 4 \mathrm{n}\right)$ reactions at a beam energy of $99 \mathrm{MeV}$. The $\mathrm{Ha}$ isotopes were detected by measuring the fission and $\alpha$ activities associated with their decay and the $\alpha$-decays of their daughters, $4-\mathrm{s}^{258} \mathrm{Lr}$ and 6-s ${ }^{259} \mathrm{Lr}$. Complete extraction-elution cycles were performed on a one-minute time scale by the computer-controlled liquid chromatography apparatus, ARCA II, using reversed-phase micro-chromatographic columns incorporating DIBC on an inert support. Stimulated by the previously observed similarity of the aqueous-phase chemistry of element 105 to that of niobium and protactinium, the extraction, from concentrated $\mathrm{HBr}$, was followed by the elution of a $\mathrm{Nb}$ fraction in $6 \mathrm{M} \mathrm{HCl} /$ $0.0002 \mathrm{M} \mathrm{HF}$, and a Pa fraction in $0.5 \mathrm{M} \mathrm{HCl}$. The number of ${ }_{262.263} \mathrm{Ha}$ decays observed in the $\mathrm{Nb}$ fraction indicated that less than $45 \%$ of the Ha was extracted into DIBC from concentrated $\mathrm{HBr}$. This was confirmed in a series of experiments in which, after the extraction, the DIBC along with all extracted species was stripped from the columns with acetone. It is concluded that, in the present chemical system, the extraction behaviour of element 105 is closer to that of niobium than to that of protactinium. The decreasing extractability from $\mathrm{HBr}$ $(\mathrm{Pa}>\mathrm{Nb}>\mathrm{Ha})$ is likely to be due to an increasing tendency of these elements to form non-extractable polynegative complex species in concentrated $\mathrm{HBr}$ in the sequence $\mathrm{Pa}<\mathrm{Nb}<\mathrm{Ha}$.
\end{abstract}

\section{Introduction}

The recently performed first studies of the aqueous chemistry of element 105 have provided both expected results and surprises [1, 2]. The sorption of $\mathrm{Ha}$ on glass surfaces after fuming twice with concentrated nitric acid was compared with tracers of the group IV elements $\mathrm{Zr}$ and $\mathrm{Hf}$ and the group $\mathrm{V}$ elements $\mathrm{Nb}$ and Ta produced under similar conditions [1]. Even after washing with $1.5 \mathrm{M} \mathrm{HNO}_{3}, \mathrm{Ha}$ was found to adhere to the glass, a property characteristic of the group $\mathrm{V}$ elements. $\mathrm{Zr}$ and $\mathrm{Hf}$, as well as the trivalent actinides, did not sorb on the glass. These experiments confirmed the expected group $\mathrm{V}$ character of $\mathrm{Ha}$, as indicated earlier by gas-phase experiments $[3,4]$. Investigations on the extraction of $\mathrm{Ha}$ into methylisobutyl ketone (MIBK) under conditions in which the lighter homolog Ta extracts, but the next lighter homolog $\mathrm{Nb}$ does not, were also conducted [1]. It was expected that $\mathrm{Ha}$ would behave more like $\mathrm{Ta}$ than $\mathrm{Nb}$ but, surprisingly, $\mathrm{Ha}$ did not extract from mixed nitric acid/hydrofluoric acid solutions although Ta did. A possible explanation is the formation of polynegative anions such as $\left[\mathrm{HaF}_{7}\right]^{2-}$. The higher charge prevents extraction, even into solvents with relatively high dielectric constants, such as MIBK.

Polynegative species are easily extracted by anion exchange into high molecular weight ammonium salts. Therefore, we have performed a large number of automated anion exchange chromatographic separations using triisooctyl amine (TIOA) on an inert support to compare the halide complexation of $\mathrm{Ha}$ in detail with the lighter group $\mathrm{V}$ elements $\mathrm{Nb}$ and $\mathrm{Ta}$, and the pseudo-group $\mathrm{V}$ element $\mathrm{Pa}$ [2]. Complete extractionelution cycles were performed on a one-minute time scale with $\mathrm{Ha}, \mathrm{Nb}, \mathrm{Ta}$, and $\mathrm{Pa}$ produced under similar conditions. It was found [2] that $\mathrm{Ha}$ sorbs on the columns from either $12 \mathrm{M} \mathrm{HCl} / 0.02 \mathrm{M} \mathrm{HF}$ or $10 \mathrm{M}$ $\mathrm{HCl}$ like its homologs $\mathrm{Nb}, \mathrm{Ta}$, and $\mathrm{Pa}$. In elutions with $4 \mathrm{M} \mathrm{HCl} / 0.02 \mathrm{M} \mathrm{HF}$ (Pa-Nb fraction), and with $6 \mathrm{M}$ $\mathrm{HNO}_{3} / 0.015 \mathrm{M} \mathrm{HF}$ (Ta fraction), the $\mathrm{Ha}$ activity was found in the $\mathrm{Pa}-\mathrm{Nb}$ fraction showing that the anionic halide complexes of $\mathrm{Ha}$ are different from those of $\mathrm{Ta}$, and are more like those of $\mathrm{Nb}$ and $\mathrm{Pa}$, indicating a reversal in the trend in going from $\mathrm{Nb}$ to $\mathrm{Ta}$ to $\mathrm{Ha}$. In another series of experiments, after the activities were 
sorbed on the TIOA from $10 \mathrm{M} \mathrm{HCl}$, elutions were performed with $10 \mathrm{M} \mathrm{HCl} / 0.025 \mathrm{M} \mathrm{HF}$ ( $\mathrm{Pa}$ fraction) and $6 \mathrm{M} \mathrm{HNO}_{3} / 0.015 \mathrm{M} \mathrm{HF}$ (stripping of the $\mathrm{Nb}$ ). The Ha activity was divided almost equally between these two fractions, showing again a behaviour very different from $\mathrm{Ta}$, and close to $\mathrm{Nb}$ and $\mathrm{Pa}$ [2]. It was suggested [2], that the non-tantalum like halide complexation of $\mathrm{Ha}$ is indicative of the formation of oxohalide or hydroxohalide complexes, like $\left[\mathrm{NbOCl}_{4}\right]^{-}$and $\left[\mathrm{PaOCl}_{4}\right]^{-}$or $\left[\mathrm{Pa}(\mathrm{OH})_{2} \mathrm{Cl}_{4}\right]^{-}$, in contrast to the pure halide complexes of Ta, like $\left[\mathrm{TaCl}_{6}\right]^{-}$.

The close similarity of the chemical behaviour of element 105 to that of $\mathrm{Pa}$ and $\mathrm{Nb}$ has motivated us to conduct additional experiments in which diisobutylcarbinol (DIBC), a secondary alcohol, was used as the extractant. This extractant has been shown repeatedly to be very selective for $\mathrm{Pa}[5,6,7]$, and well suited to perform $\mathrm{Pa}-\mathrm{Nb}$ separations $[6,7]$. In this paper, we report on the development of reversed-phase chromatographic separations of $\mathrm{Pa}$ and $\mathrm{Nb}$ in the system $\mathrm{HBr}$, $\mathrm{HCl} / \mathrm{DIBC}$, and on the application of this scheme to further assess the halide-complexation and extraction behaviour of $\mathrm{Ha}$.

\section{Distribution of $\mathrm{Nb}, \mathrm{Ta}$, and $\mathrm{Pa}$ between $\mathrm{HCl}$ and $\mathrm{HBr}$ solutions and DIBC}

\subsection{Batch extraction experiments}

In order to investigate the extraction of group 4 and 5 elements with DIBC we have performed batch extractions with pure and mixed hydrohalogenic acids. The acids were $\mathrm{HF}, \mathrm{HCl}, \mathrm{HBr}, \mathrm{HI}$, and mixtures of $\mathrm{HCl}$ with $\mathrm{HF}$. The extractant, 2,6-dimethyl-4-heptanol, also called diisobutylcarbinol, DIBC ( $99 \%$, Alfa Products), was assayed by IR-spectroscopy to confirm the absence of diisobutyl ketone, and used without further purification. The secondary alcohol was sorbed on sieved Voltalef ${ }^{R} 300$ LD-CHR (polytrifluoromonochloroethylene, Lehmann and Voss, Hamburg) with a particle size of $125-250 \mu \mathrm{m}$. The weight ratio of alcohol to support was $1: 3$. The Voltalef ${ }^{R}$ powder was mixed with a solution of DIBC in cyclohexane, which was subsequently evaporated in a stream of nitrogen. To prevent losses or oxidation of the carbinol, the powder was not heated during the evaporation of the cyclohexane.

The tracers used in the batch experiments were ${ }^{95} \mathrm{Zr},{ }^{95} \mathrm{Nb},{ }^{233} \mathrm{~Pa},{ }^{160} \mathrm{~Tb}$, and ${ }^{182} \mathrm{Ta} .{ }^{152 g} \mathrm{Eu}$ was used in the HPLC column separations. Carrier-free ${ }^{95} \mathrm{Zr}$ was isolated from fission products obtained by slow neutron irradiation of ${ }^{235} \mathrm{U} .{ }^{95} \mathrm{Nb}$ is formed via $\beta^{-}$. decay of ${ }^{95} \mathrm{Zr}$. ${ }^{233} \mathrm{~Pa}$ was prepared as the $\beta$-decay product of ${ }^{233} \mathrm{Th}$ from neutron irradiated thorium. ${ }^{160} \mathrm{~Tb}$ and ${ }^{182} \mathrm{Ta}$ were produced by neutron-activation of terbium and tantalum. All irradiations were performed at the TRIGA reactor, Mainz. Carrier-free ${ }^{152 g} \mathrm{Eu}$ was obtained commercially (Amersham Buchler, Braunschweig). Before each batch extraction experiment, aliquots of the tracer stock solutions were
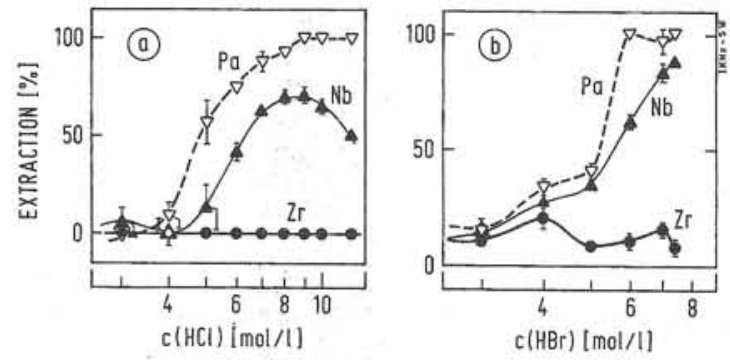

Fig. 1. Percentage of carrier-free $\mathrm{Zr}, \mathrm{Nb}$, and $\mathrm{Pa}$ extracted into DIBC a) from $\mathrm{HCl}$ solutions, and b) from $\mathrm{HBr}$ solutions.

evaporated to dryness and dissolved in the appropriate mineral acid solution.

Batches of $0.5 \mathrm{~g}$ of the powder and $2 \mathrm{ml}$ of a mineral acid solution of given molarity containing radioactive tracers of $\mathrm{Zr}, \mathrm{Nb}, \mathrm{Pa}$, and sometimes $\mathrm{Ta}$ and $\mathrm{Tb}$, were contacted in polyethylene flasks by shaking for 5 minutes. The phases were separated by centrifuging. Aliquots of the aqueous phase were assayed by $\gamma$-ray spectroscopy to determine the retention of the tracers in the aqueous phase.

It was the aim of these experiments to find conditions under which niobium and protactinium are extracted into the carbinol simultaneously, while the interfering group 4 elements are not. In the procedures described in literature $[7,8,9]$ the main focus was directed to the separation of protactinium from niobium and other interferring activities. Fig. 1 shows the extraction of $\mathrm{Zr}, \mathrm{Nb}$ and $\mathrm{Pa}$ into DIBC from $\mathrm{HCl}$ and $\mathrm{HBr}$ solutions. Pure $\mathrm{HF}$ is not suitable for this purpose, because of poor extraction yields $(10-20 \%)$ and the fact that there is no separation between $\mathrm{Zr}$ and $\mathrm{Nb} / \mathrm{Pa}$. The extraction of niobium from $\mathrm{HCl}$ reaches its maximum at $72 \%$ extraction in $8-9 \mathrm{M}$ $\mathrm{HCl}$ and drops again at higher concentrations. The insufficient extraction of $\mathrm{Nb}$ in this system at high $\mathrm{HCl}$ concentrations is likely to be due to the formation of polynegative anions such as $\left[\mathrm{NbOCl}_{5}\right]^{2-}$. The dielectric constant of DIBC is not large enough to accommodate polynegative species. To prevent the formation of non-extractable polynegative species, we selected the weaker-complexing bromide ions as ligands. In conc. $\mathrm{HBr}$, the required simultaneous extraction of $\mathrm{Pa}$ and $\mathrm{Nb}$ into DIBC is better fulfilled, see Fig. 1b. To see whether this trend continues to improve upon going to iodide ligands, we also performed a few experiments with HI, but because of its partial oxidation to iodine, which is extracted preferably [6], the extraction of $\mathrm{Pa}$ and $\mathrm{Nb}$ was adversely affected, and the system $\mathrm{HI}$ / DIBC was considered impracticable.

Since in former experiments [2] hahnium showed non tantalum-like behaviour, we performed only a few batch experiments with $\mathrm{Ta}$. It could be shown, that in pure $\mathrm{HCl}, \mathrm{Ta}$ behaves similar to $\mathrm{Nb}$, but the data should perhaps not be compared directly, because Ta and $\mathrm{Tb}$ (the latter serving as a model for the trivalent actinides) could not be obtained carrier-free and were 
therefore added in multi- $\mu$ g-quantities. Qualitatively, one observes extraction of Ta above $2 \mathrm{M} \mathrm{HCl}$ followed by a peak and a decreasing extraction yield for the highest $\mathrm{HCl}$ concentrations. For $\mathrm{Ta}$, the maximum extraction occurs at $5-6 \mathrm{M} \mathrm{HCl}$ as compared to $8-9 \mathrm{M} \mathrm{HCl}$ for $\mathrm{Nb}$, and the decrease tends to be steeper than in the case of $\mathrm{Nb}$. Both observations are likely to be connected to the even stronger tendency of Ta to form polynegative complex ions as compared to $\mathrm{Nb}$. A poor extraction yield for $\mathrm{Ta}$ in DIBC has also been described previously [9].

Taking all these results into account, and keeping in mind that all previous experiments have shown that element 105 does not behave like $\mathrm{Ta}$, the most promising approach to further studies of the chemical properties of hahnium seemed to be the simultaneous extraction of $\mathrm{Ha}$ together with $\mathrm{Nb}$ and $\mathrm{Pa}$ from concentrated $\mathrm{HBr}$ solution.

The next step was to find conditions to separate $\mathrm{Pa}$ and $\mathrm{Nb}$ from each other. Methods described in the literature $[10,11]$ give excellent separations, but are not suitable for our purposes, because solutions containing $6 \mathrm{M} \mathrm{H}_{2} \mathrm{SO}_{4}$ are employed, leading to problems in the fast preparation of weightless samples for $\alpha$ spectroscopy by evaporation. From the results shown in Fig. 1, one could draw the conclusion that a good separation is achieved by the elution of $\mathrm{Nb}$ with $12 \mathrm{M}$ $\mathrm{HCl}$. In the HPLC experiments, however, the still high extraction of $\mathrm{Nb}(50 \%)$ resulted in a delayed elution time and a broad elution peak, making this method unsuitable for a fast separation.

The addition of a small amount of HF to the $\mathrm{DIBC} / \mathrm{HCl}$ system should greatly increase the extraction of $\mathrm{Nb}$ and decrease that of $\mathrm{Pa}$ [9]. So we searched for conditions which elute $\mathrm{Pa}$ while retaining $\mathrm{Nb}$ on the column. The HF concentrations used to strip protactinium were varied from $0.1 \mathrm{M}$ to $3 \mathrm{M} \mathrm{HF}$ in $6 \mathrm{M}$ $\mathrm{HCl}[7,8,9]$. We also varied the $\mathrm{HF}$ concentration in a wider range with the $\mathrm{HCl}$ concentration at $6 \mathrm{M}$ and $9 \mathrm{M}$. The dependence of the extraction behaviour on the HF concentration is depicted in Fig. 2. In $9 \mathrm{M}$ $\mathrm{HCl}, \mathrm{Nb}$ behaves similar to $\mathrm{Pa}$ with significant differences only at higher HF concentrations, which are however not sufficient for an efficient separation. A separation is possible in $6 \mathrm{M} \mathrm{HCl}$ containing only very small amounts of HF. Under these conditions, $\mathrm{Pa}$ is retained in the organic phase while there is little extraction of $\mathrm{Nb}$. Below $0.001 \mathrm{M} \mathrm{HF}$, the extraction of $\mathrm{Nb}$ is lowered to $30 \%$, while $\mathrm{Pa}$ is still extracted quantitatively. We chose $6 \mathrm{M} \mathrm{HCl}$ containing $0.0002 \mathrm{M} \mathrm{HF}$ for the elution of $\mathrm{Nb}$, while the final stripping of the $\mathrm{Pa}$ was done with $0.5 \mathrm{M} \mathrm{HCl}$.

\subsection{HPLC column separations}

The conditions for the extraction of $\mathrm{Nb}$ and $\mathrm{Pa}$ into DIBC and possibilities for their specific elution were tested further in manually performed HPLC separations. The stationary phase was Voltalef ${ }^{R}$ powder
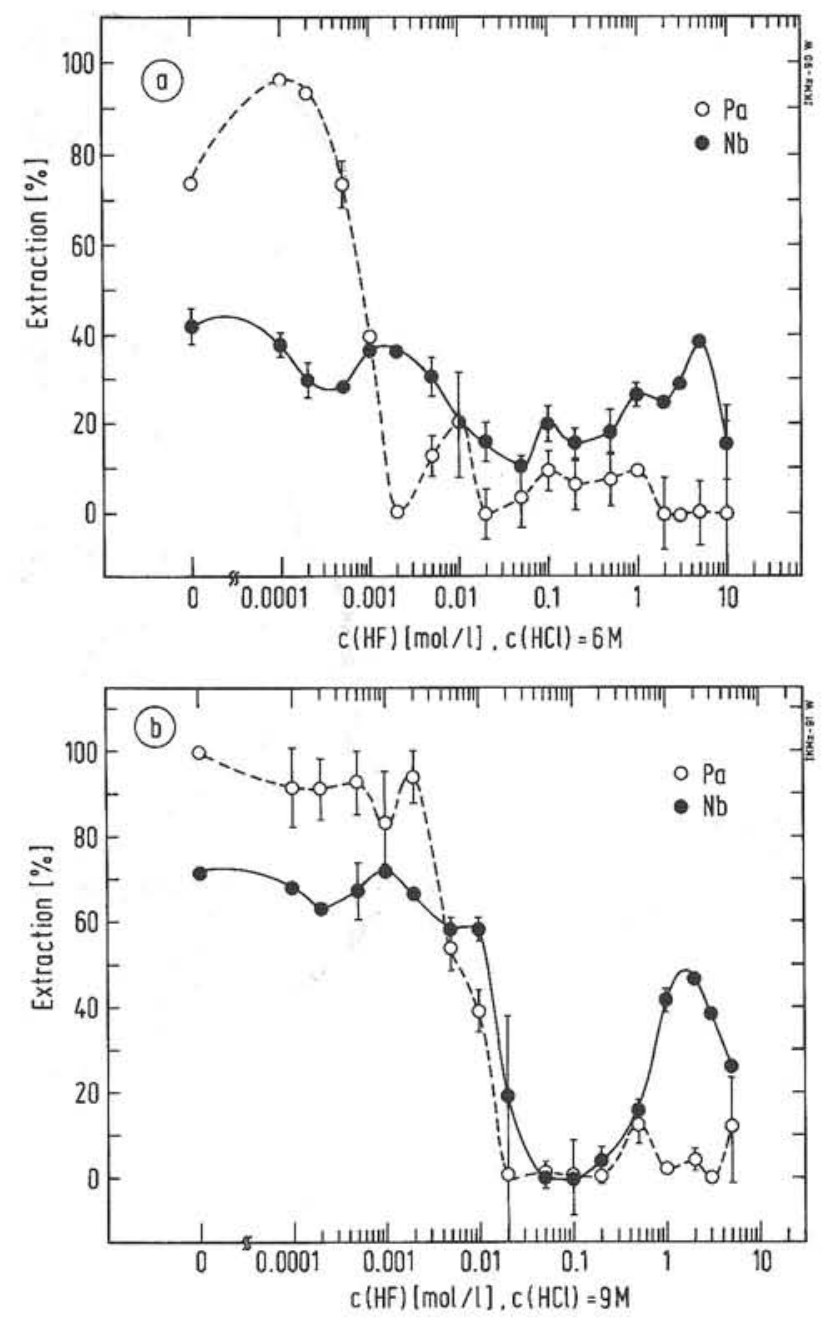

Fig. 2. Percentage of carrier-free $\mathrm{Nb}$ and $\mathrm{Pa}$ extracted into $\mathrm{DIBC}$ from a) $6 \mathrm{M} \mathrm{HCl} / \mathrm{HF}$ and b) $9 \mathrm{M} \mathrm{HCl} / \mathrm{HF}$ as a function of the $\mathrm{HF}$ concentration. $\mathrm{Zr}$ is not extracted under these conditions.

$(32-63 \mu \mathrm{m})$ as inert support coated with DIBC (weight ratio 1:3). It was packed under pressure from a slurry in water into Teflon columns of $2 \mathrm{~mm}$ i.d. and variable height. The whole system, including the pump (LATEK, Heidelberg), consisted of chemically inert materials like Teflon, Kel-F, and sapphire to prevent corrosion. Furthermore, any contact of the tracer activities to glass surfaces would lead to yield losses due to adsorption. Radioactive tracers dissolved in concentrated $\mathrm{HBr}$ were introduced through a sample loop.

The preparation of the tracer activities for these micro-chromatographic separations was found to be crucial. The presence of chloride ion decreased the extraction of $\mathrm{Nb}$ from conc. $\mathrm{HBr}$. Likewise, traces of fluoride ion lead to losses of $\mathrm{Pa}$. The presence of any other complexing agent, such as $\alpha$-hydroxyisobutyrate used to stabilize lanthanide tracers, also leads to massive perturbations, so that an extensive cleaning of the tracers was necessary. HF was destroyed by adding boric acid solution, followed by fuming several times with concentrated $\mathrm{HBr}$ in a Teflon crucible. The resi- 


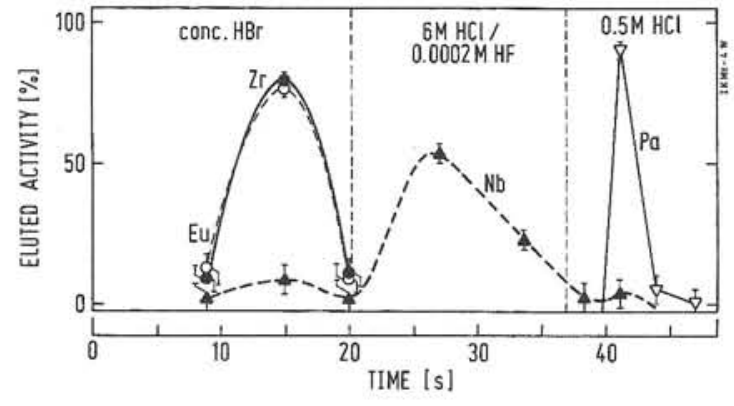

Fig. 3. Separation of $\mathrm{Eu}, \mathrm{Zr}, \mathrm{Nb}$, and $\mathrm{Pa}$ tracers applied from a sample loop to a $1.6 \times 23 \mathrm{~mm}$ DIBC/Voltalef ${ }^{R}$ column on ARCA II. The flow rate for feeding the activities onto the column in conc. $\mathrm{HBr}$ was $0.5 \mathrm{ml} / \mathrm{min}$, the elutions were conducted at $1 \mathrm{ml} / \mathrm{min}$

due was dissolved in concentrated $\mathrm{HBr}$ and used for the separations.

In addition to the radionuclides used in the batch experiments, ${ }^{1529} \mathrm{Eu}$ was used as an example for trivalent ions like the heavy actinides. It was found to elute with $\mathrm{Zr}$ in the feeding solution as suggested by Fig. 1b. $\mathrm{Pa}$ and $\mathrm{Nb}$ were sorbed on the column from conc. $\mathrm{HBr}$. $\mathrm{Nb}$ was subsequently eluted in $6 \mathrm{M} \mathrm{HCl} /$ $0.0002 \mathrm{M} \mathrm{HF}$, and then $\mathrm{Pa}$ in $0.5 \mathrm{M} \mathrm{HCl}$. Unfortunately, it was found that the extraction of $\mathrm{Nb}$ into DIBC was not quantitative even when using column heights of $20 \mathrm{~mm}$. In contrast, the extraction of $\mathrm{Pa}$ was always quantitative. The losses of $\mathrm{Nb}$ could not be avoided by using $\mathrm{HBr}$ solutions where the $\mathrm{HBr}$ concentration had been increased by further saturation with $\mathrm{HBr}$ gas.

\subsection{Automated separation with ARCA II}

The Automatic Rapid Chemistry Apparatus, ARCA II [12], consisted of three chemically inert HPLC pumps, each pumping one eluent, one conc. $\mathrm{HBr}$, one $6 \mathrm{M}$ $\mathrm{HCl} / 0.0002 \mathrm{M} \mathrm{HF}$, and the third $0.5 \mathrm{M} \mathrm{HCl}$, through Teflon tubing of $0.3 \mathrm{~mm}$ i.d. to the central Teflon unit containing various Kel-F sliders and two movable magazines containing twenty chromatographic columns $(1.6 \times 23 \mathrm{~mm})$ each. Due to the results of the manually performed HPLC separations the column heights, formerly $8 \mathrm{~mm}[2,12]$, had been increased to $23 \mathrm{~mm}$ in order to avoid unacceptable losses of $\mathrm{Nb}$ in the feeding procedure. The stationary phase was DIBC/Voltalef ${ }^{R}(32-63 \mu \mathrm{m})$, weight ratio 1:3. Tracer activities were fed onto the columns in conc. $\mathrm{HBr}$ from a sample loop at a flow rate of $0.5 \mathrm{ml} / \mathrm{min}$. The elutions were performed at $1 \mathrm{ml} / \mathrm{min}$. A typical extraction-elution cycle is shown in Fig. 3: In the feeding solution after a delay caused by the dead volume of the sample loop, $\mathrm{Eu}$ and $\mathrm{Zr}$ run through the column and are pumped into the waste. Also, some $\mathrm{Nb}$ is lost at this point due to insufficient extraction into DIBC. Typical losses were of the order of $15 \%$, but losses up to $36 \%$ were also observed. The extraction of $\mathrm{Pa}$ was quantitative. Upon a change of the aqueous phase to
$6 \mathrm{M} \mathrm{HCl} / 0.0002 \mathrm{M} \mathrm{HF}, \mathrm{Nb}$ is eluted in a relatively broad peak, which is followed by the sharply peaked elution of $\mathrm{Pa}$ in $0.5 \mathrm{M} \mathrm{HCl}$.

In the $\mathrm{Ha}$ experiments, the sample loop was omitted and the feeding time was shortened to $15 \mathrm{~s}$, as compared to the $20 \mathrm{~s}$ indicated in Fig. 3. A He-gas jet loaded with $\mathrm{KBr}$ aerosols (in one case $\mathrm{KCl}$ ) deposited the transported reaction products continuously onto one of two alternating polyethylene frits of $35 \mu \mathrm{m}$ pore size (for details see [12]). After a one minute collection, the first frit was moved to the top of one of the columns, and washed with concentrated $\mathrm{HBr}$. In this way the reaction products were dissolved, complexed, and extracted into DIBC (in case of $\mathrm{Nb}$ and $\mathrm{Pa}$ ), while the nonextractable species ran through into the waste $(\approx 15 \mathrm{~s})$. Then the column was washed with $6 \mathrm{M} \mathrm{HCl} /$ $0.0002 \mathrm{M} \mathrm{HF}$ for about 17 seconds and the effluent ( $\mathrm{Nb}$ fraction) was collected on a Ta disk and quickly evaporated to dryness by intense infrared light and hot $\mathrm{He}$ gas. Next, the $\mathrm{Pa}$ fraction was eluted in ten seconds with $0.5 \mathrm{M} \mathrm{HCl}$, collected on a Ta disc, and evaporated to dryness. The Ta discs were flamed, cooled to room temperature and inserted into the counting chamber within about $55 \mathrm{~s}$ after the end of collection. Five seconds later the next one minute collection of activity on the twin frit was completed. That frit was moved on top of another column contained in the opposite magazine and the next separation cycle was carried out. After each separation, the magazines were moved by one step, thus positioning a new column for the elution. In this way the time consuming reconditioning of used columns was avoided as well as any cross contamination. After 40 minutes of continuous collection and separation cycles the program was stopped, the used magazines were removed, two new magazines were inserted, and another 40 cycles were started. Typically 300 experiments were carried out in one shift of beam time ( 8 hours). The time sequences were optimized in test runs with carrier-free radioactive tracers of $\mathrm{Eu}, \mathrm{Zr}, \mathrm{Nb}$, and $\mathrm{Pa}$. Also, online tests of the performance of ARCA II were conducted with short-lived fission products at the TRIGA reactor, Mainz.

\section{Production, transport, and detection of ${ }^{262,263} \mathrm{Ha}$}

\subsection{Production and transport}

The nuclides $34-\mathrm{s}{ }^{262} \mathrm{Ha}$ and $27-\mathrm{s}{ }^{263} \mathrm{Ha}$ were produced at the LBL 88 -inch Cyclotron by the ${ }^{249} \mathrm{Bk}\left({ }^{18} \mathrm{O}, 5 \mathrm{n}\right)$ and the ${ }^{249} \mathrm{Bk}\left({ }^{18} \mathrm{O}, 4 \mathrm{n}\right)$ reactions. $\mathrm{A}$ $118-\mathrm{MeV}^{18} \mathrm{O}^{5+}$ beam was passed through a $2.75 \mathrm{mg} /$ $\mathrm{cm}^{2} \mathrm{Be}$ window, $0.38 \mathrm{mg} / \mathrm{cm}^{2}$ of $\mathrm{N}_{2}$ cooling gas, and the $2.49 \mathrm{mg} / \mathrm{cm}^{2}$ Be target backing before passing through the ${ }^{249} \mathrm{Bk}$ target material. The Be window was later replaced by a $1.8 \mathrm{mg} / \mathrm{cm}^{2}$ HAVAR window and the beam energy was lowered to $114 \mathrm{MeV}$. In both cases the energy of the projectiles in the target was $98-99 \mathrm{MeV}$. The target originally consisted of $542 \mu \mathrm{g} / \mathrm{cm}^{2}$ of freshly purified ${ }^{249} \mathrm{Bk}$ deposited on the 
Be backing by molecular plating and converted to the oxide in a furnace at $550^{\circ} \mathrm{C}$. During the experiments the target composition varied between $537 \mu \mathrm{g} / \mathrm{cm}^{2}$ and $516 \mu \mathrm{g} / \mathrm{cm}^{2}$ of $330-\mathrm{d}{ }^{249} \mathrm{Bk}$ due to its decay, with the remainder of the total thickness being its ${ }^{249} \mathrm{Cf}$ daughter. The beam currents varied between 0.4 and 0.5 particle microamperes. Under these conditions, the production rate was sufficient to produce an average of 0.5 alpha-decays due to ${ }^{262,263} \mathrm{Ha}$ after each oneminute irradiation. The production cross sections for the nuclides ${ }^{262} \mathrm{Ha}$ and ${ }^{263} \mathrm{Ha}$ via the $5 \mathrm{n}$ and $4 \mathrm{n}$ reaction channels at a bombarding energy of $99 \mathrm{MeV}$ are $6 \pm 3 \mathrm{nb}$ and $2 \pm 1 \mathrm{nb}$ [15], the sum of both being compatible to $8.3 \pm 2.4 \mathrm{nb}$, determined in previous experiments without differentiating between the two isotopes [2].

Because tests at the TRIGA reactor Mainz had indicated that the chloride ion concentration from the $\mathrm{He} / \mathrm{KCl}$ jet might adversely affect the extraction of $\mathrm{Nb}$, a $\mathrm{He} / \mathrm{KBr}$ jet was used in the 105 experiments (with one exception). The reaction products recoiling out of the target were stopped in He gas at $1.2 \mathrm{bar}$ which had been loaded with $\mathrm{KBr}$ aerosols produced by sublimation from the surface of $\mathrm{KBr}$ powder at $\sim 640^{\circ} \mathrm{C}$. The activity, attached to the aerosols, was swept out of the recoil chamber with the gas $(\sim 2 \mathrm{l} /$ $\mathrm{min})$ into a polyvinyl chloride capillary $(1.34 \mathrm{~mm}$ i.d. $)$ and transported $5 \mathrm{~m}$ to the collection site in ARCA II. There the gas was withdrawn by applying vacuum to the backside of a polyethylene frit on which the activity-bearing aerosols were collected. After the end of the collection time, the frit was shuttled into position for chemical processing of the activity, as described in Section 2.

The $\mathrm{He} / \mathrm{KBr}$-jet efficiency was measured frequently during the experiments. This was done by dissolving the activity in conc. $\mathrm{HBr}$ and eluting it through an empty column directly onto a Ta disc. After evaporation to dryness and flaming, the production rate of the ${ }^{252-255} \mathrm{Fm}$ transfer products was determined by $\alpha$ pulse-height analysis. Three times during the four weeks of $\mathrm{Ha}$ experiments, separate bombardments of the $\mathrm{Bk}$ target were performed in which all of the products recoiling from the target were caught in a gold catcher foil located directly behind the target. After one hour of irradiation, the foil was dissolved in aqua regia to which ${ }^{241} \mathrm{Am}$ had been added to trace the chemical yield of actinides. The gold was removed on an anion-exchange column. The actinide fraction, which passed through the column, was collected and dried on a Pt disc for alpha spectroscopy. By comparing the apparent production rates measured after transport through the $\mathrm{He} / \mathrm{KBr}$ jet with the absolute production rates measured in the gold catcher experiments, the jet efficiency was determined. The jet transport efficiency was found to vary typically between 30 and $60 \%$ during the production runs. The gas-jet yields are usually based on the measurement of 50 to 100 counts, so they are only accurate to 10 or $20 \%$.

\subsection{Detection of $\alpha$ and SF activities}

Alpha-particle and spontaneous fission (SF) fragment pulse height analyses were performed on each sample for $360 \mathrm{~s}$ using a system of ten $300 \mathrm{~mm}^{2}$ passivated ion implanted planar silicon detectors (PIPS, Canberra). The energy of each event was stored in list mode on magnetic tape along with the time after start of counting and the detector identification. Start of counting was $\approx 55 \mathrm{~s}$ after the end of collection.

The efficiency for the detection of $\alpha$ particles was $35 \%$, implying $70 \%$ efficiency for the detection of a fragment from SF decay. ${ }^{262} \mathrm{Ha}$ decays predominantly by $\alpha$ emission [15], $I_{\alpha}=67 \%, I_{\mathrm{SF}}=33 \%$. In the decay of ${ }^{263} \mathrm{Ha}$, spontaneous fission is predominating [15], $I_{\alpha}=43 \%, I_{\mathrm{SF}}=57 \%$. The $\alpha$ decay of $34-\mathrm{s}{ }^{262} \mathrm{Ha}$ $\left(E_{\alpha}=8.45-8.67 \mathrm{MeV}\right)$, is followed by the $\alpha$ decay of its daughter, $3.9-\mathrm{s}{ }^{258} \operatorname{Lr}\left(E_{\alpha}=8.57-8.65 \mathrm{MeV}\right)$ [16]. Similarly, the $\alpha$ decay of $27-\mathrm{s}{ }^{263} \mathrm{Ha}\left(E_{\alpha}=8.36 \mathrm{MeV}\right)$ is followed by the decay of ${ }^{259} \operatorname{Lr}\left(E_{a}=8.45 \mathrm{MeV}, I_{\mathrm{SF}}=\right.$ $23 \%$ ) [16]. The efficiency for detecting the parent $(35 \%)$ and missing the daughter $(65 \%)$ is $0.35 \times 0.65=$ 0.23 . Likewise, for missing the parent and detecting the daughter it is $0.65 \times 0.35=0.23$. The efficiency for detecting both $\alpha$ particles is $0.35 \times 0.35=0.12$. If the detection of both parent and daughter $\alpha$ particles is treated as the decay of two atoms, the overall efficiency for detecting the $\alpha$ decay of ${ }^{262} \mathrm{Ha}$ and ${ }^{263} \mathrm{Ha}$ (and that of their daughters, ${ }^{258} \mathrm{Lr}$ and ${ }^{259} \mathrm{Lr}$ ) is $2 \times 0.23+2 \times 0.12=0.7$. The energy resolution for $\alpha$ energies between $5 \mathrm{MeV}$ and $10 \mathrm{MeV}$ was $30 \mathrm{keV}$ at the beginning of the experiments, and increased to about twice that value towards the end. The region of interest in the $\alpha$ particle spectra is between $E_{\alpha}=8.3-$ $8.75 \mathrm{MeV}$. One can distinguish between several groups of $\alpha$-events:

$$
\begin{aligned}
& 8.300 \mathrm{MeV} \leq E_{\alpha} \leq 8.400 \mathrm{MeV} \Rightarrow{ }^{263} \mathrm{Ha} \\
& 8.400 \mathrm{MeV} \leq E_{\alpha} \leq 8.530 \mathrm{MeV} \Rightarrow{ }^{262} \mathrm{Ha} /{ }^{259} \mathrm{Lr} \\
& 8.530 \mathrm{MeV} \leq E_{\alpha} \leq 8.675 \mathrm{MeV} \Rightarrow{ }^{262} \mathrm{Ha} /{ }^{258} \mathrm{Lr} \\
& \text { 8.675 MeV } \leq E_{\alpha} \leq 8.735 \mathrm{MeV} \Rightarrow{ }^{258} \mathrm{Lr} .
\end{aligned}
$$

It is not possible to distinguish between singles of ${ }^{262} \mathrm{Ha}$ and ${ }^{258,259} \mathrm{Lr}$, because the difference between the $\alpha$ energies is of the same order of magnitude as the $\alpha$ energy resolution.

\section{Results}

Four different series of experiments were performed which totaled a number of 1019 irradiation, separation and counting cycles.

The most ambitious scheme was as follows: After extraction into DIBC from conc. $\mathrm{HBr}(15 \mathrm{~s})$ followed by an elution of the column with $6 \mathrm{M} \mathrm{HCl} / 0.0002 \mathrm{M}$ $\mathrm{HF}$ for $7 \mathrm{~s}$ into the waste in order to improve the decontamination from the actinides, a $\mathrm{Nb}$ fraction was eluted in $6 \mathrm{M} \mathrm{HCl} / 0.0002 \mathrm{M} \mathrm{HF}(12 \mathrm{~s})$, followed by stripping of $\mathrm{Pa}$ in $0.5 \mathrm{M} \mathrm{HCl}(9 \mathrm{~s}$; Run $\mathrm{A})$. In 100 experiments only $1 \alpha$ event and 4 spontaneous fission (SF) events attributable to ${ }^{262,263} \mathrm{Ha}$ were recorded in 
Table 1. Summary of the various DIBC runs performed on hahnium isotopes produced in the ${ }^{249} \mathrm{Bk}\left({ }^{18} \mathrm{O}, 5 \mathrm{n}\right)$ and ${ }^{249} \mathrm{Bk}\left({ }^{18} \mathrm{O}, 4 \mathrm{n}\right)$ reactions at $99 \mathrm{MeV}$ bombarding energy

\begin{tabular}{lccccc}
\hline Designation & Jet & \# of expts. & \# of $\alpha$ 's & \# of SF's & $\sigma[\mathrm{nb}]$ \\
\hline Run A-Nb & $\mathrm{KBr}$ & 99 & 1 & 4 & $3.3 \pm 2.3$ \\
Run A-Pa & $\mathrm{KBr}$ & 100 & 0 & 1 & $0.7 \pm 1.1$ \\
Acetone strips & $\mathrm{KBr}$ & 320 & 7 & 7 & $3.7 \pm 2.1$ \\
"early Nb" & $\mathrm{KCl}$ & 127 & 2 & 1 & $2.1 \pm 1.7$ \\
"early Nb" & $\mathrm{KBr}$ & 263 & 4 & 2 & $1.8 \pm 1.2$ \\
$\mathrm{~Pa}$ & $\mathrm{KBr}$ & 110 & 0 & 1 & $0.8 \pm 0.8$ \\
$\Sigma$ without Pa & & 809 & 14 & 14 & $2.7 \pm 1.8$ \\
$\Sigma$ & & 1019 & 14 & 16 & $2.3 \pm 1.6$ \\
\hline
\end{tabular}

the $\mathrm{Nb}$ fraction and $1 \mathrm{SF}$ event in the $\mathrm{Pa}$ fraction. Despite the low statistical significance it was felt that, compared to the production rates expected from the known cross section for the production of isotopes of hahnium at this bombarding energy, $8.3 \pm 2.4 \mathrm{nb}$ [2], the observed rate was too low by at least a factor of two.

In order to check whether the extraction conditions were adequate, "acetone strips" were performed in analogy to those previously performed in our TIOA experiments [2]. After extraction of the activities into the DIBC from conc. $\mathrm{HBr}(18 \mathrm{~s})$, the DIBC (along with all extracted activities) was stripped from the inert support by dissolving it in acetone (12 s). The acetone strip fraction was evaporated to dryness and assayed for $\alpha$ particle and SF decay starting $45 \mathrm{~s}$ after the end of the collection cycle. In 320 experiments, $7 \alpha$ events and $7 \mathrm{SF}$ events attributable to the decay of ${ }^{262,263} \mathrm{Ha}$ were detected, yielding in an apparent sum cross section for ${ }^{262} \mathrm{Ha}+{ }^{263} \mathrm{Ha}$ of $3.7 \pm 2.1 \mathrm{nb}$ to be compared with the $8.3 \pm 2.4 \mathrm{nb}$ determined previously [2]. Thus, the acetone strips confirmed the earlier suspicion that the extraction yield of element 105 into $\mathrm{DIBC}$ from conc. $\mathrm{HBr}$ was incomplete, in qualitative agreement with the behaviour of $\mathrm{Nb}$, but different from that of Pa.

In a third series of experiments comprising 390 separation cycles, a $\mathrm{Nb}$ fraction was stripped from the DIBC columns for $15 \mathrm{~s}$, starting immediately after the end of the feeding in conc. $\mathrm{HBr}(18 \mathrm{~s})$, thus omitting the intermittent washing for $7 \mathrm{~s}$ as in run $\mathrm{A}$. The cycle time was again $45 \mathrm{~s}$. In these "early Nb fractions", $6 \alpha$ and $3 \mathrm{SF}$ events attributable to the decay of ${ }^{262,263} \mathrm{Ha}$ were registered, corresponding to an apparent cross section of $1.9 \pm 1.2 \mathrm{nb}$. About one third of these experiments were run with a $\mathrm{He} / \mathrm{KCl}$ jet rather than $\mathrm{He} /$ $\mathrm{KBr}$, giving raise to unfavourably high concentrations of chloride ions, which lead to low extraction yields for niobium under the given conditions, as it is known from the test experiments at the Mainz TRIGA reactor. However, for Hahnium no significant difference in the extraction yield was observed.
Finally, the distribution of the extracted ${ }^{262,263} \mathrm{Ha}$ species among the $\mathrm{Nb}$ and $\mathrm{Pa}$ fractions was investigated further by elution of a $\mathrm{Pa}$ fraction in $0.5 \mathrm{M} \mathrm{HCl}$ from the DIBC columns after loading them from conc. $\mathrm{HBr}$. In 110 experiments only one SF decay was registered, corresponding to an apparent cross section of $0.8 \pm 0.8 \mathrm{nb}$.

A summary of the various experiments using DIBC as extractant is given in Table 1 . Within the error limits, the apparent cross sections for ${ }^{262} \mathrm{Ha}+{ }^{263} \mathrm{Ha}$ in the acetone strips and the $\mathrm{Nb}$ fractions are consistent with each other. The same is true for the very low apparent cross sections for the $\mathrm{Pa}$ fractions in Run $\mathrm{A}$ and in the final series of experiments.

\section{Discussion}

The recorded $14 \alpha$ events and 16 (14) SF events have $\alpha$ particle energies and/or decay times, that are compatible with the known decay characteristics of 34-s ${ }^{262} \mathrm{Ha}[1,2,13]$, and $27-\mathrm{s}{ }^{263} \mathrm{Ha}[15]$, as compiled in Table 2 . For the detector geometry of $35 \%$ of $4 \pi$, we should observe, among these 14 events, 2.3 pairs of correlated mother-daughter $\alpha$ decays. None were observed, which is not at variance with expectations based on statistical fluctuations in small numbers $(10 \%$ probability from a poisson distribution).

The apparent cross sections for the ${ }^{262,263} \mathrm{Ha}$ event rates in the $\mathrm{Nb}$ fractions and in the acetone strips (see Table 1) are definitely lower than the previously determined production cross section of $8.3 \pm 2.4 \mathrm{nb}$ [2], which covers the production of both isotopes, ${ }^{262} \mathrm{Ha}$ and ${ }^{263} \mathrm{Ha}$. We interpret this in terms of a low extraction yield of element 105 into DIBC from concentrated $\mathrm{HBr}$ solution on the order of $30 \%$ to $40 \%$ only. This is even lower than the extraction yields of $\mathrm{Nb}$ which were typically between $64 \%$ and $85 \%$. Thus, the present data and the tracer studies point to an increasing extraction yield in the sequence $105<\mathrm{Nb}<\mathrm{Pa}$. The distribution of ${ }^{262,263} \mathrm{Ha}$ events between the $\mathrm{Nb}$ and $\mathrm{Pa}$ fractions, Table 1, tends to corroborate that conclusion. 
Table 2. Alpha events between 8.3 and $8.73 \mathrm{MeV}$ in the experiments using DIBC as an extractant. For the assignment of events to the decay of ${ }^{262} \mathrm{Ha}$ and ${ }^{258,259} \mathrm{Lr}$, see also Section 3.2

\begin{tabular}{|c|c|c|c|c|}
\hline Designation & Detector & $\begin{array}{l}\text { Energy } \\
{[\mathrm{MeV}]}\end{array}$ & $\begin{array}{l}\text { Lifetime } \\
{[\mathrm{s}]}\end{array}$ & Assignment \\
\hline Run $\mathrm{A}-\mathrm{Nb}$ & 7 & 8.713 & 69.48 & ${ }^{258} \mathrm{Lr}$ \\
\hline Acetone strips & $\begin{array}{c}3 \\
7 \\
9 \\
4 \\
10 \\
3 \\
5\end{array}$ & $\begin{array}{l}8.50^{a} \\
8.48^{a} \\
8.512 \\
8.572 \\
8.432 \\
8.451 \\
8.543\end{array}$ & $\begin{array}{r}\text { short }^{a} \\
\text { short }^{a} \\
1.35 \\
6.55 \\
3.23 \\
6.55 \\
0.05\end{array}$ & $\begin{array}{l}{ }^{262} \mathrm{Ha} /{ }^{259} \mathrm{Lr} \\
{ }^{262} \mathrm{Ha} /{ }^{259} \mathrm{Lr} \\
{ }^{262} \mathrm{Ha} /{ }^{259} \mathrm{Lr} \\
{ }^{262} \mathrm{Ha} /{ }^{258} \mathrm{Lr} \\
{ }^{262} \mathrm{Ha} /{ }^{259} \mathrm{Lr} \\
{ }^{262} \mathrm{Ha} /{ }^{259} \mathrm{Lr} \\
{ }^{262} \mathrm{Ha} /{ }^{258} \mathrm{Lr}\end{array}$ \\
\hline "early Nb", KBr-Jet & $\begin{array}{l}7 \\
7 \\
6 \\
4\end{array}$ & $\begin{array}{l}8.340 \\
8.455 \\
8.620 \\
8.489\end{array}$ & $\begin{array}{r}4.15 \\
144.95 \\
209.15 \\
35.92\end{array}$ & $\begin{array}{c}{ }^{263} \mathrm{Ha} \\
{ }^{262} \mathrm{Ha} /{ }^{259} \mathrm{Lr} \\
{ }^{262} \mathrm{Ha} /{ }^{258} \mathrm{Lr} \\
{ }^{262} \mathrm{Ha} /{ }^{259} \mathrm{Lr}\end{array}$ \\
\hline "early Nb", KCl-Jet & $\begin{array}{l}6 \\
4\end{array}$ & $\begin{array}{l}8.684 \\
8.353\end{array}$ & $\begin{array}{l}135.50 \\
195.43\end{array}$ & $\begin{array}{l}{ }^{258} \mathrm{Lr} \\
{ }^{263} \mathrm{Ha}\end{array}$ \\
\hline
\end{tabular}

${ }^{a}$ The exact energies and lifetimes of these two events were lost due to a failure of the data acquisition system.

The extraction into DIBC is restricted to neutral or singly charged metal complexes [14], while polynegative species like $\left[\mathrm{TaBr}_{7}\right]^{2-}$ or $\left[\mathrm{NbOBr}_{5}\right]^{2-}$ cannot be extracted. The present results indicate that the tendency of element 105 to form polynegative complexes at high halide concentration is stronger than for $\mathrm{Nb}$ and much stronger than for Pa. From the present study, it is not clear whether this is a true shift in the equilibrium constant for the equilibrium

$$
\left[\mathrm{MeOBr}_{4}\right]^{-}+\mathrm{Br}^{-} \rightleftharpoons\left[\mathrm{MeOBr}_{5}\right]^{2-} \text {, }
$$

or a shift towards slower kinetics of complex formation in the case of hahnium as compared to $\mathrm{Nb}$ and $\mathrm{Pa}$.

In summary, we have performed a series of reversed-phase chromatographic separations of element 105 in the system $\mathrm{DIBC} / \mathrm{HBr}, \mathrm{HCl}$. The extraction yield of bromide complexes of element 105 from concentrated $\mathrm{HBr}$ solutions into DIBC was typically around $40 \%$ only. In back extractions with $6 \mathrm{M} \mathrm{HCl} /$ $0.0002 \mathrm{M} \mathrm{HF}$, element 105 was found in the $\mathrm{Nb}$ fractions. The data suggest that in concentrated halide solutions, the strength of polynegative metal complexes decreases in the order $\mathrm{Ha}>\mathrm{Nb}>\mathrm{Pa}$.

\section{Acknowledgements}

The authors are indebted to the Division of Chemical Sciences, Office of Basic Energy Sciences, U.S. Department of Energy, for making the ${ }^{249} \mathrm{Bk}$ target material available through the transplutonium element production facilities at the Oak Ridge National Laboratory.

We like to thank Dr. N. Trautmann and S. Zauner for advice and help, and the staff and crew of the TRIGA reactor Mainz for assistance in the test phase of the experiment.
We wish to thank the staff and crew of the LBL 88 -inch Cyclotron for providing the ${ }^{18} \mathrm{O}$ beams and for technical support.

The German and Swiss groups have enjoyed the hospitality of the Lawrence Berkeley Laboratory $\mathrm{Nu}$ clear Science Division.

This work was supported by the German Federal Minister for Research and Technology (BMFT) under contract No. 03-HE2MAI, by the Director Office of Energy Research, Office of Basic Energy Sciences, Chemical Sciences Division of the U.S. Department of Energy under Contract No. DE-AC03-76SF00098, and by the Swiss National Science Foundation under Contract No. 2.204-0.86.

\section{References}

1. Gregorich, K. E., Henderson, R. A., Lee, D. M., Nurmia, M. J., Chasteler, R. M., Hall, H. L., Bennett, D. A., Gannett, C. M., Chadwick, R. B., Leyba, J. D., Hoffman, D. C., Herrmann, G.: Radiochim. Acta 43, 223 (1988).

2. Kratz, J. V., Zimmermann, H. P., Scherer, U. W., Schädel, M., Brüchle, W., Gregorich, K. E., Gannett, C. M., Hall, H. L., Henderson, R. A., Lee, D. M., Leyba, J. D., Nurmia, M. J., Hoffman, D. C., Gäggeler, H., Jost, D., Baltensperger, U., Ya Nai-Qi, Türler, A., Lienert, Ch.: Radiochim. Acta 48, 121 (1989).

3. Zvara, I., Eichler, B., Belov, V. Z., Zvarova, T. S., Korotkin, Yu. S., Hussonnois, M.: Sov. Radiochem. 16, 709 (1974).

4. Zvara, I., Belov, V. Z., Domanov, V. P., Shalaevskii, M. R.: Sov. Radiochem. 18, 328 (1976).

5. Scherff, H. L., Herrmann, G.: Radiochim. Acta 6, 53 (1966).

6. Denig, R., Trautmann, N., Herrmann, G.: Z. Anal. Chem. 216, 41 (1966)

7. Trautmann, N., Denig, R., Herrmann, G.: Radiochim. Acta 11, 168 (1969).

8. Scherff, H. L., Herrmann, G.: Z. Elektrochem. 64, 1022 (1964).

9. Casey, A. T., Maddock, A. G.: J. Inorg. Nucl. Chem. 10, 289 (1959). 
10. Moore, F. L.: Anal. Chem. 27, 70 (1955)

11. Fudge, A. J., Woodhead, J. L.: Chem. Ind. 1957, 1022.

12. Schädel, M., Brüchle, W., Jäger, E., Schimpf, E., Kratz, J. V., Scherer, U. W., Zimmermann, H. P.: Radiochim. Acta 48, 171 (1989)

13. Ghiorso, A., Nurmia, M., Eskola, K., Eskola, P.: Phys. Rev. C4, 1850 (1971).

14. Markl, P.: Extraktion und Extraktionschromatographie in der Anorganischen Chemie, in: Methoden der Analyse in der Chemie, Vol. 13, Akademische Verlagsgesellschaft, Frankfurt (1972).
15. Kratz, J. V., Gober, M. K., Zimmermann, H. P., Schädel, M., Brüchle, W., Schimpf, E., Gregorich, K. E., Türler, A., Hannink, N. J., Czerwinski, K. R., Kadkhodayan, B., Lee, D. M., Nurmia, M. J., Hoffman, D. C., Gäggeler, H., Jost, D., Kovacs, J., Scherer, U. W., Weber, A.: Phys. Rev. C, in print (GSI-preprint 91-32).

16. Gregorich, K. E., Hall, H. L., Henderson, R. A., Leyba, J. D., Czerwinski, K. R., Kreek, S. A., Kadkhodayan, B. A., Nurmia, M. J., Lee, D. M., Hoffman, D. C.: Phys. Rev. C, in print (LBL-preprint 30548). 